\title{
Acquisition of the two-way avoidance response in chicken compared to rat and cat'
}

E. E. KRIECKHAUS ANO WILLIAM J. WAGMAN

POULTRY HUSBANDRY DEPARTMENT, UNIVERSITY OF CALIFORNIA AT DAVIS

Three groups of White Leghorn chickens acquired a twoway avoidance response as quickly as rats and slightly more slowly than cats.

The most salient morphological difference between the diencephalon of mammals and infra-mammals is the presence of the mammillothalamic system in the former (for a discussion see Krieckhaus, 1966). This difference is particularly striking as one ascends the phylogenetic scale within mammalia. It is well established that sectioning of the pathway from the mammillary bodies to the anterior thalamic nuclei (mammillothalamic tractotomy) produces a profound deficit in the retention of the difficult conditioned avoidance response in two species of mammalia-cat (Thomas, Fry, Fry, Slotnick, \& Krieckhaus, 1963; Krieckhaus, 1964; Krieckhaus \& Chi, 1966) and rat (Krieckhaus, 1965). The above observations raise the question of whether infra-mammals might not be deficient in the acquisition of such avoidance responses since they appear to be deficient in a neural system which seems to mediate this behavior in higher organisms. Although it is admittedly difficult to compare specific learning tasks between greatly different species, the above question was explored in the present study by training chickens in the two-way (shuttle) avoldance response, which is one of the responses found to be adversely effected in both rat and cat by mammillothalamic tractotomy.

\section{Method}

The Ss consisted of three groups, each consisting of five, single-comb, White Leghorn cockerels. Groups 1 and 3 were between 12 to 14 weeks of age at the onset of training, while Group 2 was approximately 20 weeks of age.

The apparatus, a plywood box $91 \mathrm{~cm}$ long, $78.5 \mathrm{~cm}$ high, and $64.0 \mathrm{~cm}$ wide, was divided into two equal halves by a gulllotine door. The floor of the apparatus consisted of steel bars $8 \mathrm{~mm}$ in diameter, spaced $2 \mathrm{~cm}$ apart. One wall of the apparatus was made of Plexiglas. A $60 \mathrm{~Hz}, 2000 \mathrm{~V}$ variable transformer, the output of which was in series with a $400 \mathrm{~K}$ ohm resistance, delivered a current of $5 \mathrm{~mA}$ maximum to the grid floor. Because of the extremely high and variable resistance of the birds' feet it was difficult, even with an oscilloscope, to obtain an accurate measure of current levels actually employed. However, the current was approximately 4-5 $\mathrm{mA}$. The CS, an attenuated door buzzer, was located on the side of the apparatus, between the two compartments. The Ss in Groups 1 and 2 were trained in a standard shuttle-avoidance procedure similar to that employed earlier with cats (Krieckhaus, 1964) and rats (Krieckhaus, 1965), except that a 5 sec rather than a 10 sec CS-US interval was used. The intertrial interval was $1 \mathrm{~min}$. All Ss were trained for 10 trials the first day and 20 trials every day thereafter until they reached the criterion of 17 correct responses out of the 20 trials for three consecutive days, or until they had been trained for 11 days. The animals in Group 3 were treated the same as those in the first two groups except that the door was removed from the apparatus and the birds were free to move from side to side during the intertrial interval (an intertrial response). Shock was administered in the side of the apparatus in which the bird happened to be at the end of the intertrial interval. Resulis

Of the 15 animals, only four failed to reach the criteria within the 11 days of testing. Learning curves for each of the three groups of chickens are presented in Fig. 1. For comparison, data on 36 cats, including the

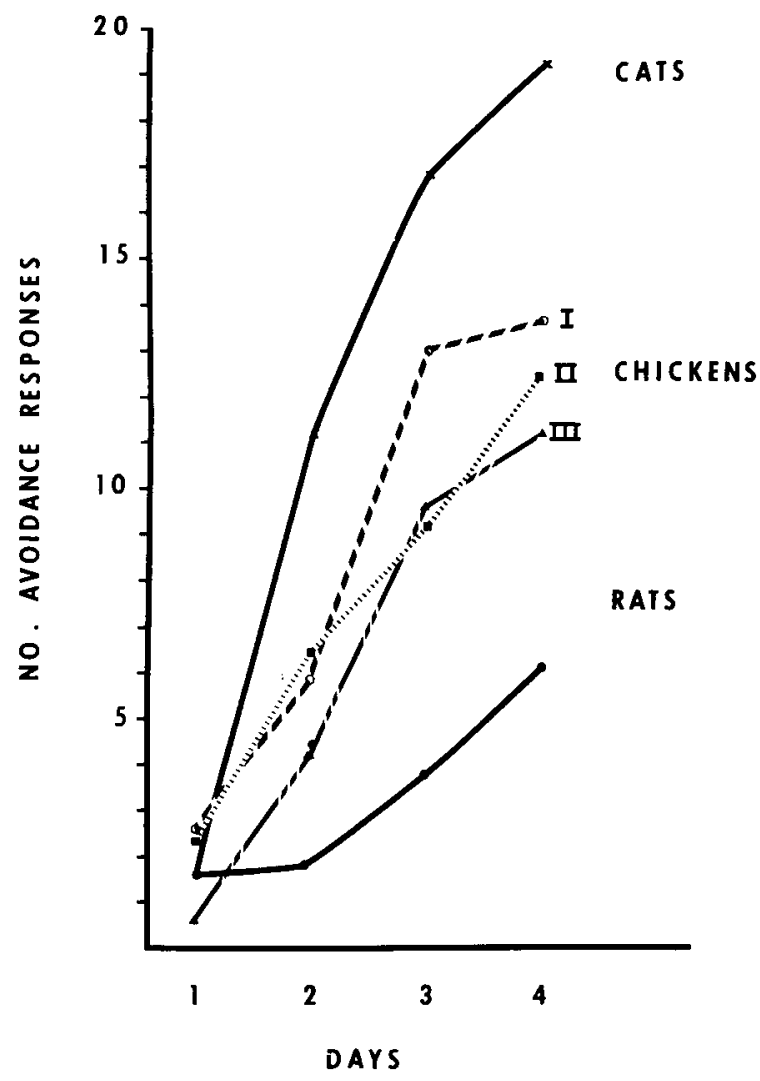

Fig. 1. Acquisition of the two-way avoidance response for chickens, cats and rats. 
27 cats reported earlier (Krieckhaus, 1964) and data on 16 rats reported earlier (Weiss, Krieckhaus, \& Conte, 1966), are also presented in the figure. It is clear that the data offer no support for the view that chickens would have great difficulty in acquiring the two-way avoidance response.

Analysis of the intertrial responses of Group 3 revealed that from the onset of training three of the five birds averaged less than 15 intertrial responses per day, i.e., less than one per trial. This indicates that the good performance of these birds was not simply attributable to their learning to move from one end of the box to the other whenever they could; they were responding selectively to the CS. On the other hand, one bird, whose avoidance performance was as good as that of the other three, averaged almost 200 intertrial responses per day, i.e., 10 per trial. The fifth animal, which was inferior in avoidance performance to the other four, after 12 days of training began to improve its performance from a level of approximately 10 avoidance responses per session to a level of 19 responses by the 18th day; in this same period it also reduced its number of intertrial responses from approximately 100 to 25 per day. Discussion

Results of this study clearly demonstrate that at least one species of Aves (Gallus domesticus) is capable of acquiring the difficult two-way avoidance response as readily as two common experimental species of mammalia (Felis domestica and Ratus ratus). This finding has important implications for any theory of avoidance behavior which would incorporate phylogenetic and neurophysiological variables. It is now well demonstrated in both cat and rat that integrity of the mammillothalamic system is essential for adequate retention of a preoperatively acquired two-way avoidance response. However, this system is apparently poorly developed or absent in Aves (Kappers, Huber, \& Crosby, 1960; Krieckhaus, 1966), yet, as shown in the present study, the domestic fowl is capable of acquiring this response as readily as cat and rat. A similar situation appears to exist for bony fishes, which also have only a rudimentary mammillothalamic system (Kappers, Huber, \& Crosby, 1960), and which also a re quite capable of acquiring the two-way avoidance response (Behrend \& Bitterman, 1964).

These findings suggest that in at least some infra- mammalian species the two-way avoidance response, however it may be conceptualized, is either mediated by structures other than the mammillothalamic system or that this system, rudimentary as it may be, does exist in infra-mammals and does mediate difficult avoldance behavior. Alternatively, since the most dramatic effects of mammillothalamic tractotomy in mammals has been on retention of difficult avoidance behavior and since the present work has dealt with acquisition of this behavior, it may be that acquisition and retention of difficult avoidance behavior may have different neural bases. However this issue may be resolved, the present study indicates that considerably more investigation of phylogenettc, neurophysiological, anatomical, and behavior variables must be accomplished before these variables can be fruitfully integrated in aid of understanding the difficult problem of the function of the prominent mammalian mammillothalamic system.

\section{References}

Behrend, E. R., \& Bitteman, M. E. Avoidance-conditioning in the fish: further studies of the CS-US interval. Amer. J. Psychol, $1964,77,15-28$.

Kappers, C. U. A., Huber, G. C., \& Crosby, E. C. The comparative anatomy of the nervous system of vertebrates, including man. New York: Hafner, 1960.

Krieckhaus, E. E. Decrements in avoidance behavior following mammillothalamic tractotomy in cats. J. Neurophysiol., 1964, $27,753-767$.

Krieckhaus, E. E. Decrements in avoidance behavior following mammillothalamic tractotomy in rats and subsequent recovery with d-amphetamine. J. comp. physiol. Psychol., 1965, 60, 31-35.

Krieckhaus, E. E. The mammillary bodies: their function and anatomical connections. Paper presented at the Symposium on functional properties of the hypothalamus, September 16, 1966, in Lublin, Poland.

Krieckhaus, E. E., \& Chi, C. C. Role of freezing and fear in avoidance decrements following mammillothalamic tractotomy in cat: I. Two-way avoidance behavior. Psychon. Sci., 1966, 4, 263-264.

Thomas, G. J., Fry, W. J., Fry, F. J., Slotnick, B. M., \& Krieckhaus, E. E. Behavioral effects of mammillothalamic tractotomy in cats. J. Neurophysiol., 1963, 26, 857-876.

Weiss, J. Krieckhaus, E. E., \& Conte, R. Effects of fear conditioning on subsequent avoldance and movement. Paper read at East. Psychol. Assoc., New York, April, 1966.

\section{Note}

1. This research was supported by Grant HD-02621 from the National Institute of Child Health and Human Development to the University of California. 